\title{
Clinical effect of single covered stent and double covered stent on TIPS in the treatment of hemorrhage due to rupture of esophageal and gastric varices in cirrhosis and its influence on immune function
}

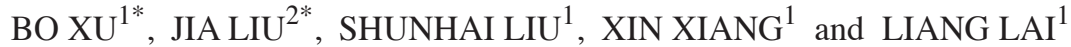 \\ Departments of ${ }^{1}$ Hepatobiliary Surgery and ${ }^{2}$ Anesthesiology, \\ The First People's Hospital of Neijiang, Neijiang, Sichuan 641000, P.R. China
}

Received July 8, 2019; Accepted September 2, 2019

DOI: $10.3892 /$ etm.2019.8106

\begin{abstract}
Clinical effect of single covered stent and double covered stent in transjugular intrahepatic portosystemic shunt (TIPS) in the treatment of hemorrhage due to rupture of esophageal and gastric varices in cirrhosis and its influence on the immune function of patients was investigated. Altogether 124 patients with liver cirrhosis and esophageal and gastric varices bleeding who were admitted to the First People's Hospital of Neijiang from February 2012 to April 2016 were selected as research objects and divided into group A and B. Group A (65 cases) was treated with simple covered stent, and group B (59 cases) was treated with double covered stent simulating Viatorr technique. The therapeutic effect of the two groups after operation was observed. The changes of portal vein pressure before and after treatment and the changes of esophageal and gastric varices after operation were observed. The levels of peripheral blood $\mathrm{T}$ lymphocyte subsets $\left(\mathrm{CD}^{+}, \mathrm{CD}^{+}\right.$and $\left.\mathrm{CD} 4^{+} / \mathrm{CD}^{+}\right)$were detected by flow cytometry. The therapeutic effect of group B was higher than that of group $\mathrm{A}(\mathrm{P}>0.05)$. The postoperative portal vein pressure in group B was significantly lower than that in group A $(\mathrm{P}<0.05)$. The disappearance rate and overall effective rate of varicose veins in group $B$ were better than those in group $A$ $(\mathrm{P}>0.05)$. After three days of treatment, the levels of $\mathrm{CD}^{+}$, $\mathrm{CD}^{+}, \mathrm{CD}^{+} / \mathrm{CD}^{+}$in the peripheral blood of group $\mathrm{B}$ were higher than those of group $\mathrm{A}(\mathrm{P}>0.05)$, while the decline rate of $\mathrm{CD}^{+}, \mathrm{CD}^{+}, \mathrm{CD}^{+} / \mathrm{CD}^{+}$in the peripheral blood of group B was higher than that of group A after seven days of
\end{abstract}

Correspondence to: Dr Liang Lai, Department of Hepatobiliary Surgery, The First People's Hospital of Neijiang, 31 Tuozhong Road, Neijiang, Sichuan 641000, P.R. China

E-mail: i563jn@163.com

*Contributed equally

Key words: hemorrhage due to rupture of esophageal and gastric varices in cirrhosis, single coated stent, double stent, immune function treatment. Double-stent simulated Viatorr has a higher effective rate, has a certain improvement on the immune function of patients, and the survival rate is also higher than that of single covered stent, which is worthy of clinical application and promotion.

\section{Introduction}

Cirrhosis is diffuse liver damage induced by various chronic hepatitis diseases for a long time or under the influence of repeated actions. With the aggravation of the disease course, portal hypertension will occur in patients leading to esophageal and gastric varices (1-4). Esophageal and gastric varices are the common causes of gastrointestinal hemorrhage. Esophagogastric varices rupture hemorrhage is one of the serious clinical complications of cirrhosis due to large amount of hemorrhage, dangerous onset and high mortality rate (5-7).

Clinically, TIPS technology is widely used to treat esophageal and gastric variceal bleeding caused by portal hypertension. TIPS is a minimally invasive method to establish stents to artificially distribute blood, which reduces portal pressure to prevent esophageal and gastric variceal bleeding (8-10). However, the restenosis rate of blood shunts and the incidence rate of hepatic encephalopathy are high after TIPS is used, and the mid- and long-term curative effects of patients after treatment are poor, which are defects of TIPS technology. With the appearance of covered stent, evidence-based medicine shows that the stenosis rate of blood shunt after covered stent is significantly improved, but there are still some adverse prognosis problems $(11,12)$. Subsequently, FID of the United States recommended using Viatorr stent for TIPS (13), but the stent price is higher and the usage rate is lower. Therefore, clinical workers simulated Viatorr stent and applied double stents in TIPS (14-16). As the clinical efficacy of double stent simulated Viatorr stent in TIPS, is not very clear we studied and compared the clinical efficacy of single covered stent and double stents in TIPS for the treatment of cirrhotic esophageal and gastric variceal bleeding, providing certain reference for clinical treatment of cirrhotic esophageal and gastric variceal bleeding under pressure. 


\section{Patients and methods}

Collection of specimens. Altogether 124 patients with liver cirrhosis and esophageal and gastric varices bleeding admitted to the First People's Hospital of Neijiang (Neijiang, China) from February 2012 to April 2016 were selected as research objects and divided into groups A and B. Among them, 65 patients with simple covered stent were selected as group A, including 47 males and 18 females, with an average age of $43.5 \pm 2.3$ years. Another 59 patients treated with double stent technique simulating Viatorr method were taken as group B, including 38 males and 21 females, with an average age of $42.8 \pm 2.8$ years.

This study was approved by the Medical Ethics Committee of the First People's Hospital of Neijiang. Patients who participated in this research had complete clinical data. Signed informed consents were obtained from the patients or the guardians.

Inclusion and exclusion criteria. Inclusion criteria: Patients were diagnosed as cirrhosis and with complete clinical data; with poor therapeutic effect through drugs and endoscopy and high risk of surgical operation; without cerebrovascular diseases and malignant tumor diseases; who can be followed up and with Budd-Chiari syndrome.

Exclusion criteria: Patients with coagulation dysfunction, severe infectious diseases, combined with other liver and kidney diseases, hepatic vein occlusion, or polycystic liver disease.

Treatment methods. Firstly, according to the patient's imaging data, the positional relationship between hepatic vein and portal vein was determined before operation to ensure the safety of the puncture route. The patient was required to take the supine position, the operation site was disinfected and anesthetized. The position relationship between hepatic vein and portal vein was determined again after preoperative preparation to ensure the accuracy of the puncture. The puncture position was the right internal jugular vein of the patient, and the portal vein pressure was measured after the puncture was confirmed to be successful and the position was appropriate. The varicose vein was embolized by springs according to the direct portal angiography result. After the puncture was completed, a balloon catheter was introduced to expand the intrahepatic puncture under fluoroscopy, and a stent was selected according to the incision of the balloon. The covered stent was required not to block the ipsilateral portal vein blood flow in human liver. Double stents were first implanted with bare stents to connect the portal vein, and then implanted with film or bare stents. The stents were released in a precise location. After completion, the walking and expansion of stents in the shunt were observed again through direct portal venography. After confirmation, the catheter could be removed, and then the puncture opening was bandaged.

Postoperative treatment and follow-up. After the operation, the puncture point of the patient was pressed to stop bleeding, blood routine and liver function of the patient were tested, and anticoagulants were administered orally every day. All patients were followed up by telephone and outpatient review
Table I. Evaluation criteria for efficacy.

\begin{tabular}{ll}
\hline Grade & \multicolumn{1}{c}{ Criteria } \\
\hline Markedly effective & $\begin{array}{l}\text { Hemostasis within } 8 \mathrm{~h}, \text { no black stool } \\
\text { and haematemesis within 2 weeks. }\end{array}$ \\
Effective & $\begin{array}{l}\text { Hemostasis within 24 h, no black stool } \\
\text { and haematemesis within 2 weeks. } \\
\text { Active bleeding was still present } \\
\text { within 24 h and recurrence occurred } \\
\text { within 2 weeks. }\end{array}$ \\
\hline
\end{tabular}

Table II. Grading criteria of esophagogastric varices.

\begin{tabular}{llc}
\hline Grade & \multicolumn{1}{c}{$\begin{array}{c}\text { Form of esophageal } \\
\text { varicosis (F) }\end{array}$} & $\begin{array}{c}\text { Red color } \\
\text { (RC) }\end{array}$ \\
\hline $\begin{array}{l}\text { Mild (G1) } \\
\text { Moderate }\end{array}$ & $\begin{array}{l}\text { Straight or slightly circuitous (F1) } \\
\text { (G2) }\end{array}$ & No \\
Severe & Snake roundabout uplift (F2) & Yes \\
(G3) & Snake roundabout uplift (F2) & No \\
& Beads, nodules, tumors (F3) & No or yes
\end{tabular}

for two years after surgery, every three months in the first year of follow-up and every six months in the second year of follow-up. The follow-up ended in April 2018.

Observation indicators. Main observation indicators: The clinical efficacy of two groups of patients after different stent operations was observed (Table I) as well as the immune function of patients after operation.

Secondary observation indicators: The changes of portal vein pressure before and after operation in the two groups, and the changes of esophageal and gastric varices in the two groups were observed (Table II). The survival conditions of the groups two years after operation were recorded.

Statistical analysis. SPSS 19.0 software (SPSS Inc.) was used in this study for statistical analysis. GraphPad Prism 7 software was used to visualize the data in this study. The enumeration data was expressed by rate (\%) and detected by Chi-square test, while the measurement data was expressed by mean \pm standard deviation (mean \pm SD). Independent sample t-test was used to compare the two groups, and K-M survival curve was used to analyze the recurrence of patients within two years. Statistical significance is indicated by $\mathrm{P}<0.05$

\section{Results}

General clinical data of groups $A$ and $B$. There was no difference in age, sex, BMI $\left(\mathrm{kg} / \mathrm{m}^{2}\right)$, liver function Child-Pugh classification, etiology of liver cirrhosis, preoperative portal vein width, residence, smoking, alcoholism and other general clinical baseline data between groups $\mathrm{A}$ and $\mathrm{B}$ (P>0.05) (Table III). 
Table III. General clinical data of groups A and B [n (\%)].

\begin{tabular}{|c|c|c|c|c|}
\hline Factor & $A(n=65)$ & $B(n=59)$ & $\mathrm{t} / \chi^{2}$ value & P-value \\
\hline Sex & & & 0.896 & 0.344 \\
\hline Male & $47(72.31)$ & $38(64.41)$ & & \\
\hline Female & $18(27.69)$ & $21(35.59)$ & & \\
\hline Age (years) & $43.5 \pm 2.3$ & $42.8 \pm 2.8$ & 1.527 & 0.129 \\
\hline BMI $\left(\mathrm{kg} / \mathrm{m}^{2}\right)$ & $24.35 \pm 1.72$ & $23.87 \pm 1.69$ & 1.565 & 0.120 \\
\hline Liver function Child-Pugh grading & & & 0.505 & 0.477 \\
\hline Grade A & $30(46.15)$ & $31(52.54)$ & & \\
\hline Grade B & $35(53.85)$ & $28(47.46)$ & & \\
\hline Etiology of liver Cirrhosis & & & 1.110 & 0.775 \\
\hline Posthepatitic B Cirrhosis & $32(49.23)$ & $26(44.07)$ & & \\
\hline Posthepatitic C Cirrhosis & $5(7.69)$ & $3(5.08)$ & & \\
\hline Alcoholic cirrhosis & $7(10.77)$ & $6(10.17)$ & & \\
\hline Others & $21(32.31)$ & $24(40.68)$ & & \\
\hline Preoperative portal vein width $(\mathrm{cm})$ & $1.27 \pm 0.14$ & $1.34 \pm 0.21$ & 2.202 & 0.030 \\
\hline Residence & & & 1.343 & 0.247 \\
\hline Urban & $44(67.69)$ & $34(57.63)$ & & \\
\hline Rural & $21(32.31)$ & $25(42.37)$ & & \\
\hline Smoking history & & & 0.016 & 0.898 \\
\hline Yes & $29(44.62)$ & $27(45.76)$ & & \\
\hline No & $36(55.38)$ & $32(54.24)$ & & \\
\hline Drinking history & & & 0.482 & 0.488 \\
\hline Yes & $36(55.38)$ & $29(49.15)$ & & \\
\hline No & $29(44.62)$ & $30(50.85)$ & & \\
\hline
\end{tabular}

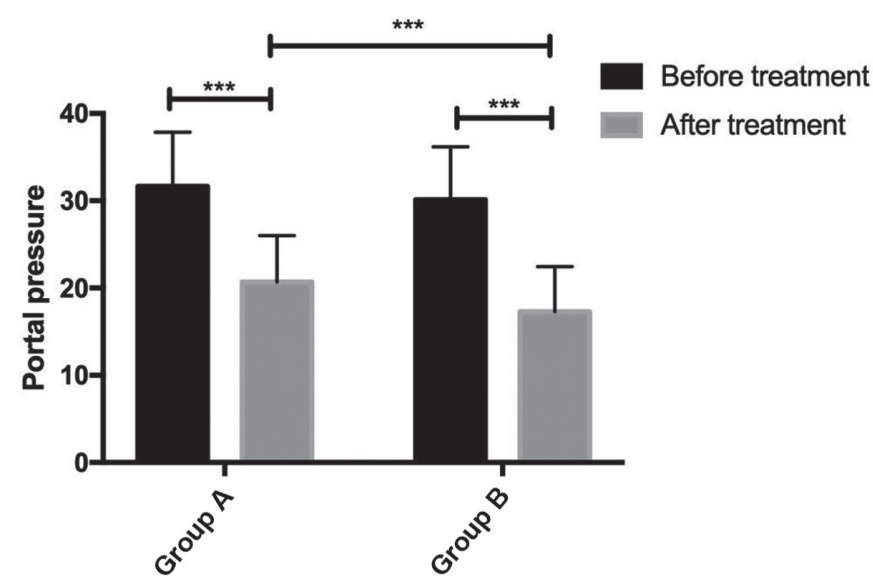

Figure 1. Changes of portal vein pressure before and after operation in the two groups. There were significant differences between pre-treatment and post-treatment in group A $(\mathrm{P}<0.001, \mathrm{t}=10.800)$, there were significant differences between pre-treatment and post-treatment in group $\mathrm{B}(\mathrm{P}<0.001$, $t=12.370$ ), there was no difference between groups $A$ and $B$ before treatment $(\mathrm{P}>0.05)$, there were significant differences between groups $\mathrm{A}$ and $\mathrm{B}$ after treatment $(\mathrm{P}<0.001, \mathrm{t}=3.577) .{ }^{* * *} \mathrm{P}<0.001$.

Evaluation of curative effect of two groups of patients. Comparing the curative effect evaluation of the two groups of patients, it was found that the total effective rate of group A was $83.08 \%$, and of B was $93.22 \%$. The total effective rate of patients in group $\mathrm{B}$ was higher than that in group $\mathrm{A}(\mathrm{P}>0.05)$ (Table IV).
The changes of portal vein pressure before and after operation in the two groups. Preoperative portal pressure in group A was $31.64 \pm 6.21$ and postoperative portal pressure was $20.67 \pm 5.34$. Preoperative portal pressure in group B was $30.12 \pm 6.07$ and postoperative portal pressure was $17.29 \pm 5.16$. There was no difference in portal vein pressure between the two groups $(\mathrm{P}>0.05)$. The portal vein pressure in group B was significantly lower than that in group A $(\mathrm{P}<0.05)$ (Fig. 1).

Comparison of changes of esophagogastric varices between two groups. The degree of esophageal and gastric varices after operation in both groups was significantly improved compared with that before operation. The disappearance rate and overall effective rate of varicose veins in group B were better than those in group A ( $\mathrm{P}>0.05)$ (Table V).

Changes of immune function in two groups of patients. The changes of $\mathrm{CD}^{+}, \mathrm{CD}^{+}$and $\mathrm{CD}^{+} / \mathrm{CD}^{+}$before treatment, 3 and 7 days after treatment in the two groups were observed. Compared with the changes of $\mathrm{CD}^{+}, \mathrm{CD}^{+}$and $\mathrm{CD}^{+} / \mathrm{CD}^{+}$ 3 and 7 days after treatment in group $A$, there was no statistical difference $(\mathrm{P}>0.05)$. After treatment for 3 days in group $\mathrm{B}$, $\mathrm{CD}^{+}, \mathrm{CD}^{+}$and $\mathrm{CD}^{+} / \mathrm{CD}^{+}$were higher than those in group A. After 7 days of treatment, the decrease rate of $\mathrm{CD}^{+}$, $\mathrm{CD}^{+}$and $\mathrm{CD}^{+} / \mathrm{CD}^{+}$in group $\mathrm{B}$ was higher than that in group A $(\mathrm{P}>0.05)$ (Table VI). 
Table IV. Efficacy evaluation of two groups of patients $[\mathrm{n}(\%)]$.

\begin{tabular}{|c|c|c|c|c|}
\hline & $A(n=65)$ & $B(n=59)$ & $\chi^{2}$ value & P-value \\
\hline Markedly effective & $25(38.46)$ & $32(54.24)$ & 3.099 & 0.078 \\
\hline Effective & $29(44.62)$ & $23(38.98)$ & 0.403 & 0.536 \\
\hline Ineffective & $11(16.92)$ & $4(6.78)$ & 2.993 & 0.084 \\
\hline Total effective & $54(83.08)$ & $55(93.22)$ & 2.993 & 0.084 \\
\hline
\end{tabular}

Table V. Degree of esophagogastric varices in two groups of patients after treatment.

\begin{tabular}{|c|c|c|c|c|}
\hline Degree of varicose & $A(n=65)$ & $B(n=59)$ & $\chi^{2}$ value & P-value \\
\hline G1 & $26(40.00)$ & $25(42.37)$ & 0.072 & 0.789 \\
\hline G2 & $16(24.62)$ & $14(23.73)$ & 0.013 & 0.908 \\
\hline G3 & $12(18.46)$ & $5(8.47)$ & 2.607 & 0.106 \\
\hline Disappearance & $11(16.92)$ & $15(25.42)$ & 1.349 & 0.246 \\
\hline
\end{tabular}

Table VI. Changes of $\mathrm{CD}^{+} \mathrm{CD}^{+}$and $\mathrm{CD}^{+} / \mathrm{CD}^{+}$before, after 3 and 7 days of treatment in the two groups of patients.

\begin{tabular}{|c|c|c|c|c|c|c|c|c|c|}
\hline \multirow[b]{2}{*}{ Groups } & \multicolumn{3}{|c|}{$\mathrm{CD}^{+}$} & \multicolumn{3}{|c|}{$\mathrm{CD}^{+}$} & \multicolumn{3}{|c|}{$\mathrm{CD}^{+} / \mathrm{CD}^{+}{ }^{+}$} \\
\hline & $\begin{array}{c}\text { Before } \\
\text { treatment }\end{array}$ & $\begin{array}{c}\text { Three } \\
\text { days after } \\
\text { treatment }\end{array}$ & $\begin{array}{c}\text { Seven } \\
\text { days after } \\
\text { treatment }\end{array}$ & $\begin{array}{c}\text { Before } \\
\text { treatment }\end{array}$ & $\begin{array}{c}\text { Three } \\
\text { days after } \\
\text { treatment }\end{array}$ & $\begin{array}{c}\text { Seven } \\
\text { days after } \\
\text { treatment }\end{array}$ & $\begin{array}{c}\text { Before } \\
\text { treatment }\end{array}$ & $\begin{array}{c}\text { Three } \\
\text { days after } \\
\text { treatment }\end{array}$ & $\begin{array}{c}\text { Seven } \\
\text { days after } \\
\text { treatment }\end{array}$ \\
\hline$A(n=65)$ & $50.35 \pm 6.23$ & $53.47 \pm 4.75$ & $52.32 \pm 4.43$ & $43.12 \pm 5.07$ & $46.87 \pm 5.11$ & $43.47 \pm 4.06$ & $0.83 \pm 0.34$ & $1.25 \pm 0.39$ & $0.92 \pm 0.36$ \\
\hline$B(n=59)$ & $50.87 \pm 6.45$ & $55.23 \pm 5.47$ & $51.07 \pm 3.23$ & $42.69 \pm 4.58$ & $48.32 \pm 4.72$ & $42.13 \pm 3.89$ & $0.76 \pm 0.28$ & $1.36 \pm 0.42$ & $0.82 \pm 0.31$ \\
\hline t value & 0.649 & 1.917 & 1.780 & 0.494 & 1.636 & 1.872 & 1.244 & 1.512 & 1.649 \\
\hline P-value & 0.456 & 0.057 & 0.078 & 0.622 & 0.104 & 0.064 & 0.216 & 0.133 & 0.102 \\
\hline
\end{tabular}

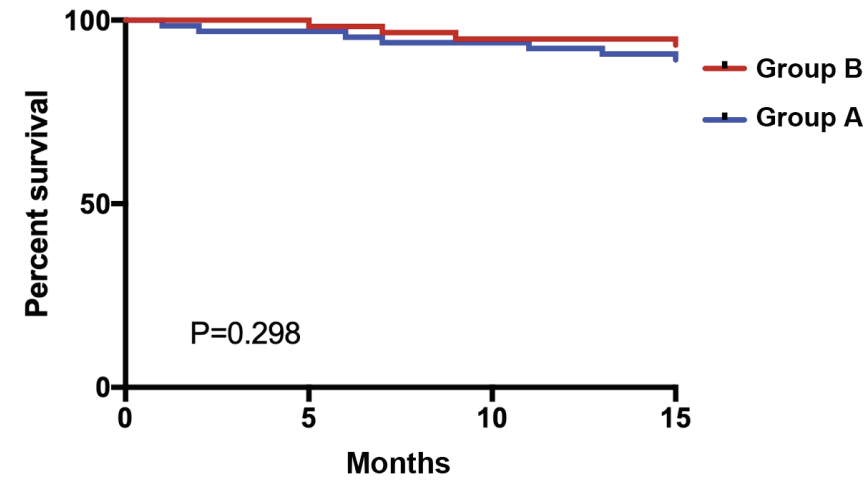

Figure 2. Two-year survival of two groups of patients. All patients were followed up for two years and the survival rate was $90.32 \%$. The two-year survival rate of group A was $87.69 \%$, of group B was $93.22 \%$; group B was higher than that of group A $(\mathrm{P}=0.298)$.

Two-year survival of two groups of patients. Statistics on the survival of the two groups of patients were made for two years. Altogether 124 patients or their families were followed up, with 0 patients lost to follow-up. Within two years, 12 patients died, 112 survived, with a survival rate of $90.32 \%$. Eight patients died in group A, 57 survived, and the survival rate was $87.69 \%$. Four patients died in group B, 55 survived, and the survival rate was $93.22 \%$. The two-year survival rate of the patients in group B was higher than that in group $\mathrm{A}$, with no statistical significance $(\mathrm{P}=0.298)$ (Fig. 2).

\section{Discussion}

Esophagogastric varices are common complications of liver cirrhosis. Liver cirrhosis is pathologically defined as liver, which leads to metabolic liver failure and portal hypertension $(17,18)$. Portal hypertension is the most common complication of liver cirrhosis, and esophageal varices are portal mesangium of patients with liver cirrhosis with portal hypertension (19). Every year, a certain proportion of cirrhotic patients develop esophageal varices, which is the main cause of death for cirrhotic patients (20). TIPS is the main treatment method for esophageal varices rupture and hemorrhage. In recent years, the appearance of covered stent and double-stent simulated Viatorr methods have further optimized TIPS treatment (21). Therefore, this study investigated the efficacy of the two stent methods in TIPS.

We compared the clinical efficacy of covered stent and double stent in TIPS treatment of liver cirrhosis patients with esophageal and gastric varices bleeding. The results showed 
that the therapeutic efficacy of patients with double stent was higher than that of patients with single covered stent. In the study of Sommer et al (22), the hemodynamics, patency rate and complications of Viatorr stent in TIPS treatment were higher than those of bare metal stent, and the clinical success rate was better than those of bare metal stent, which was similar to our results. Furthermore, we compared the therapeutic effects of single covered stent and double stents (i.e. simulated Viatorr stent method) in TIPS. The single covered stent was improved on the basis of bare metal stents and was more effective than bare metal stents in preventing variceal rebleeding. This view has also been confirmed in the study conducted by Bucsics et al (23). However, the appearance of Viator stents in the United States provides a new concept in TIPS therapy. In our study, we also show that the simulated Viatorr double stent method has better curative effect, which further supports our research results. In addition, we also observed that the portal vein pressure of patients applying the two stent methods is lower than that of patients applying single covered stent. In the study of the Zhao et al (24), the portal vein pressure of patients after Viatorr stent treatment was reduced, which was similar to our results. We speculate that the double stent can effectively improve the patency of the shunt and reduce the pressure of the shunt to prevent varicose veins. Double stents are used to simulate Viatorr stents with the same effect for TIPS therapy, further supporting our research results. Moreover, we observed that the varicose degree of patients after both stent operations was improved, and the varicose disappearance rate in patients using double stents was higher. Then, we observed the immune function of patients after surgery. Compared with patients with single covered stent, the immune function of patients with double covered stent increased three days after surgery, and the rate of recovery was higher than that of patients with single covered stent. According to the recovery of patients' immune function, we consider that the double covered stent method can effectively reduce bleeding symptoms and complications. In the study of Ferral et al (15), Viatorr stent, which is the double covered stent we simulated, has excellent shunt unblocking rate and better therapeutic effect. After two years of follow-up investigation, the results showed that the survival rate of patients with double stents is higher than that of patients with single covered stents, which suggests that the application of double stents in TIPS may be beneficial to the survival of patients.

This study initially proved that the clinical effect of double stents in TIPS treatment of liver cirrhosis esophageal and gastric fundus varices hemorrhage is better, but this study still has certain limitations as we did not study the complications of patients and did not make a good prognosis. The number of samples and the research time need to be increased in the follow-up studies.

In conclusion, double stents are more effective in TIPS in the treatment of liver cirrhosis with esophageal and gastric variceal bleeding, promoting the rapid recovery of immune function, and are worthy of clinical application and promotion.

\section{Acknowledgements}

Not applicable.

\section{Funding}

The study was funded by the project of 'Clinical application of TIPS in the treatment of ePTFE covered stent in cirrhotic portal hypertension', Neijiang Bureau of Science, Technology and Intellectual Property (no. 2016105).

\section{Availability of data and materials}

The datasets used and/or analyzed during the present study are available from the corresponding author on reasonable request.

\section{Authors' contributions}

BX wrote the manuscript. BX, JL and LL conceived and designed the study, and drafted the manuscript. BX, JL, SL and XX collected, analyzed and interpreted the experimental data. LL revised the manuscript for important intellectual content. All the authors read and approved the final manuscript.

\section{Ethics approval and consent to participate}

This study was approved by the Medical Ethics Committee of the First People's Hospital of Neijiang (Neijiang, China). Patients who participated in this research had complete clinical data. Signed informed consents were obtained from the patients or the guardians.

\section{Patient consent for publication}

Not applicable.

\section{Competing interests}

The authors declare that they have no competing interests.

\section{References}

1. Krzyżanowska P, Drzymała-Czyż S, Pogorzelski A, Duś-Żuchowska M, Skorupa W, Bober L, Sapiejka E, Oralewska B, Rohovyk N, Moczko J, et al: Vitamin K status in cystic fibrosis patients with liver cirrhosis. Dig Liver Dis 49: 672-675, 2017.

2. Wu KC, Huang HC, Chang T, Lee WS, Chuang CL, Hsin IF, Hsu SJ, Lee FY, Chang CC and Lee SD: Effect of sirolimus on liver cirrhosis and hepatic encephalopathy of common bile duct-ligated rats. Eur J Pharmacol 824: 133-139, 2018.

3. Pimenta JR, Ferreira AR, Fagundes ED, Queiroz TC, Baptista RA, de Araújo Moreira EG, de Resende CB, Bittencourt PF, Carvalho SD, Neto JA, et al: Factors associated with bleeding secondary to rupture of esophageal varices in children and adolescents with cirrhosis. J Pediatr Gastroenterol Nutr 64: e44-e48, 2017.

4. Saito H, Ohmori M, Iwamuro M, Tanaka T, Wada N, Yasunaka T, Takaki A and Okada H: Hepatic and gastric involvement in a case of systemic sarcoidosis presenting with rupture of esophageal varices. Intern Med 56: 2583-2588, 2017.

5. Kim DJ, Darcy MD, Mani NB, Park AW, Akinwande O, Ramaswamy RS and Kim SK: Modified balloon-occluded retrograde transvenous obliteration (BRTO) techniques for the treatment of gastric varices: Vascular plug-assisted retrograde transvenous obliteration (PARTO)/coil-assisted retrograde transvenous obliteration (CARTO)/balloon-occluded antegrade transvenous obliteration (BATO). Cardiovasc Intervent Radiol 41: 835-847, 2018.

6. Fullwood D: Portal hypertension and varices in patients with liver cirrhosis. Nurs Stand 26: 52-57, quiz 58, 2012. 
7. El Ray A, Azab MM,El-Aziz IM,El-Aleem AA, El-Talkawy MD, El-Badea MA, El Ansary M, Safeem AA and Diab TM: Non-invasive predictors for the presence, grade and risk of bleeding from esophageal varices in patients with post-hepatitic cirrhosis. J Egypt Soc Parasitol 45: 421-428, 2015.

8. Lv Y, Yang Z, Liu L, Li K, He C, Wang Z, Bai W, Guo W, Yu T, Yuan X, et al; AVB-TIPS Study Group: Early TIPS with covered stents versus standard treatment for acute variceal bleeding in patients with advanced cirrhosis: A randomised controlled trial. Lancet Gastroenterol Hepatol 4: 587-598, 2019.

9. Maimone S, Saffioti F, Filomia R, Alibrandi A, Isgrò G, Calvaruso V, Xirouchakis E, Guerrini GP, Burroughs AK, Tsochatzis E, et al: Predictors of re-bleeding and mortality among patients with refractory variceal bleeding undergoing salvage transjugular intrahepatic portosystemic shunt (TIPS) Dig Dis Sci 64: 1335-1345, 2019.

10. Lv Y, Zuo L, Zhu X, Zhao J, Xue H, Jiang Z, Zhuge Y, Zhang C, Sun J, Ding P, et al: Identifying optimal candidates for early TIPS among patients with cirrhosis and acute variceal bleeding: A multicentre observational study. Gut 68: 1297-1310, 2019.

11. Wang L, Xiao Z, Yue Z, Zhao H, Fan Z, Zhao M, He F, Dai S, Qiu B, Yao J, et al: Efficacy of covered and bare stent in TIPS for cirrhotic portal hypertension: A single-center randomized trial. Sci Rep 6: 21011, 2016.

12. Bureau C, Garcia-Pagan JC, Otal P, Pomier-Layrargues G, Chabbert V, Cortez C, Perreault P, Péron JM, Abraldes JG, Bouchard L, et al: Improved clinical outcome using polytetrafluoroethylene-coated stents for TIPS: Results of a randomized study. Gastroenterology 126: 469-475, 2004.

13. Vignali C, Bargellini I, Grosso M, Passalacqua G, Maglione F, Pedrazzini F, Filauri P, Niola R, Cioni R and Petruzzi P: TIPS with expanded polytetrafluoroethylene-covered stent: Results of an Italian multicenter study. AJR Am J Roentgenol 185: 472-480, 2005.

14. Geeratikun Y, Timmermans H, Uchida B, Jahangiri Y, Horikawa M, Kaufman JA and Farsad K: VIDEO: Technique to restrict the gore viatorr stent-graft for TIPS reduction. AJR Am J Roentgenol 210: W172-W172, 2018.

15. Ferral H, Gomez-Reyes E and Fimmel CJ: Post-transjugular intrahepatic portosystemic shunt follow-up and management in the VIATORR era. Tech Vasc Interv Radiol 19: 82-88, 2016.

16. Cai W, Zhuge Y, Zhang J, Li Z, He Q, Zhang M, Ni J, Li Y, Ma Q and Peng C: Safety and clinical efficacy of TIPS with various stents for treatment of cirrhosis with esophageal gastric varices bleeding. Zhonghua Gan Zang Bing Za Zhi 23: 258-264, 2015 (In Chinese).
17. Nan YM: Current status and perspectives of diagnosis and treatment of complications related to liver cirrhosis. Zhonghua Gan Zang Bing Za Zhi 25: 241-245, 2017 (In Chinese).

18. Hung TH, Liang CM, Hsu CN, Tai WC, Tsai KL, Ku MK, Wang JW, Tseng KL, Yuan LT, Nguang SH, et al: Association between complicated liver cirrhosis and the risk of hepatocellular carcinoma in Taiwan. PLoS One 12: e0181858, 2017.

19. Gioia S, Nardelli S, Pasquale C, Pentassuglio I, Nicoletti V, Aprile F, Merli M and Riggio O: Natural history of patients with non cirrhotic portal hypertension: Comparison with patients with compensated cirrhosis. Dig Liver Dis 50: 839-844, 2018.

20. Wasfy E, Elkassas G, Elnawasany S, Elkasrawy K, Abd-Elsalam S, Soliman S and Badawi R: Predicting esophageal varices in cirrhotic hepatitis $C$ virus patients using noninvasive measurement of insulin resistance variables. Endocr Metab Immune Disord Drug Targets 18: 573-580, 2018.

21. Qi X, Tian Y, Zhang W, Yang Z and Guo X: Covered versus bare stents for transjugular intrahepatic portosystemic shunt: An updated meta-analysis of randomized controlled trials. Therap Adv Gastroenterol 10: 32-41, 2017.

22. Sommer CM, Gockner TL, Stampfl U, Bellemann N, Sauer P, Ganten T, Weitz J, Kauczor HU and Radeleff BA: Technical and clinical outcome of transjugular intrahepatic portosystemic stent shunt: Bare metal stents (BMS) versus viatorr stent-grafts (VSG). Eur J Radiol 81: 2273-2280, 2012.

23. Bucsics T, Schoder M, Diermayr M, Feldner-Busztin M, Goeschl N, Bauer D, Schwabl P, Mandorfer M, Angermayr B, Cejna M, et al: Transjugular intrahepatic portosystemic shunts (TIPS) for the prevention of variceal re-bleeding - A two decades experience. PLoS One 13: e0189414, 2018.

24. Zhao JB, Ye P, Zeng QL, Pang HJ, He XF and Chen Y: Transjugular intrahepatic portosystemic shunt with Viatorr stent grafting: Report of 3 cases. Nan Fang Yi Ke Da Xue Xue Bao 36: 294-296, 2016 (In Chinese).

This work is licensed under a Creative Commons Attribution-NonCommercial-NoDerivatives 4.0 International (CC BY-NC-ND 4.0) License. 